\title{
"Buscarás la justicia y solo la justicia" (Deuteronomio 16, 20) Lecturas y reflexiones ético-cristianas para tiempos de crisis económica*
}

\section{José Ignacio González Faus, Centro de Cristianismo y Justicia, Barcelona}

La crisis económica, tanto la española como la mundial, ha desencadenado una gran cantidad de literatura que es casi imposible de abarcar, a menos que escribiéramos otro libro más. En este texto, elijo algunos libros que, por un afán formal de compleción (ya que no puedo ser materialmente completo), me gustaría dividir en tres capítulos: (1) el pasado o historia de la crisis; (2) nuestro presente en la lucha contra ella; y (3) algunas lecciones para el futuro (aunque es probable que no las aprendamos si es cierto que "el hombre es el único animal que tropieza dos veces en la misma crisis).

\section{Historia de la crisis}

En este capítulo seré mucho más breve porque los orígenes de la crisis pertenecen ya al pasado. Pero puede ser útil evocar dos libros en trazos rápidos.

Leopoldo Abadía, La crisis ninja y otros misterios de la economía actual, Madrid, 2010

Un libro breve y pedagógico que tuvo el mérito de ser uno de los primeros en trazar esa línea sinuosa que va desde la decisión de un particular norteamericano

* El autor, bien conocido de nuestros lectores, ofrece un boletín de las últimas publicaciones sobre la "crisis" en un mundo globalizado. Su interés inmediato es iluminar al lector español, pero con mayor razón ilumina a los lectores de países como El Salvador, que sufren la "crisis" con mucha mayor crueldad. 
de prestar dinero a malos pagadores para resarcirse con unos intereses más altos o unas apropiaciones cuyo valor iba creciendo hasta el desmoronamiento global de todas las economías. La aparente neutralidad del libro puede ser completada con la siguiente obra.

\section{Ernesto Ekaizer, Indecentes. Crónica de un atraco perfecto, Barcelona, 2012}

Un periodista conocido, combativo, buen analista y bien informado. Por si no estuviera claro lo que indica el título, este libro lleva un antetítulo que reza: Por qué lo llaman crisis cuando es una estafa. Y resumiendo una de sus tesis fundamentales, puede formularse así: "Existen intereses creados que obstaculizan la capacidad intelectual de economistas y analistas" (p. 51).

Como ejemplo de esas cegueras intelectuales, puede servir la afirmación de Rodrigo Rato en 2002: "No estamos ante una burbuja; estamos ante una demanda muy poderosa que se mantiene, aunque se está moderando" (p. 66). Que nos evoca la tantas veces citada de Zapatero unos años después: "No estamos ante una crisis". Aun aceptando que el interés que los cegó fue el de crear optimismo y no pesimismo, lo innegable es la ceguera de ambas afirmaciones. Y el ejemplo cumbre, y reconocido, son estas palabras del señor Greenspan (presidente de la Reserva Federal de EE. UU.) en 2008 ante el Congreso de su país: "Todavía no entiendo completamente por qué ha ocurrido" (p. 86). Una frase así, ante algo tan clamoroso y que se podía ver venir, solo se explica porque esos intereses creados le cegaron los ojos. A menos que queramos admitir que Greenspan sabía bien que estaba empujando al mundo hacia el abismo, pero tenía intereses personales (o grupales) para embarcarse en ese riesgo.

En este marco de intereses creados, nos recuerda el autor que De Guindos, en 2006, fue nombrado presidente ejecutivo de Lehman Brothers ${ }^{1}$ para España y Portugal (p. 43). Es como decirnos qué es lo que podíamos esperar de un ministro tal.

\section{Salidas de la crisis}

\section{Paul Krugman, ¡Acabad ya con esta crisis!, Crítica, 2012}

La obra de este premio Nobel es un alegato en favor de políticas keynesianas, que son las que nos sacaron de la crisis anterior y que hoy son rechazadas interesadamente por los grandes poderes de la tierra que están ya más a la derecha de Milton Friedman (pp. 141-142). El autor señala que Obama fue más keynesiano al comienzo (entre 2009 y 2011), pero acabó entrando en el juego conservador.

1. El banco de inversiones, cuya caída desencadenó toda la crisis. 
Intentaremos sistematizar el libro recurriendo a una especie de "índice temático" personal.

1. Diagnóstico. El resultado de la crisis está siendo así: (a) Los riquísimos todavía más ricos y los trabajadores normales o clases medias cada vez más pobres (pp. 83-95). (b) "La prolongada debilidad de la economía pasará factura en su potencia a largo plazo" (p. 24). Esto quiere decir que recuperarnos no será volver a lo de antes, y que pasará mucho tiempo hasta que (aun estando ya fuera de la crisis) recuperemos los niveles de bienestar anteriores a ella. Sobre todo, las víctimas tendrán que seguir pasándolo peor. Y (c) "Lo más indignante es que no hay ninguna necesidad de que pase lo que está pasando: no ha venido una plaga de langostas ni hemos perdido nuestra pericia tecnológica” (p. 29). Solo ha ocurrido lo que el autor describe con una frase espléndida de Upton Sinclair, y que concreta la palabra interés subrayada en párrafos anteriores: "Es difícil conseguir que un hombre comprenda algo cuando su salario depende de que no lo comprenda" (p. 97).

2. Tesis del libro. "Si las cosas que normalmente se consideran adecuadas y prudentes nos hacen ir a peor en la situación actual, ¿no supone esto que, de hecho, deberíamos estar haciendo lo contrario? Y la respuesta, básicamente, es sí. En un momento en que muchos deudores intentan aumentar el ahorro y cancelar las deudas, es importante que alguien haga lo contrario, es decir: gaste más y tome más dinero prestado. $\mathrm{Y}$ ese alguien no es otro que el Gobierno... Para responder a la clase de depresión a que nos enfrentamos necesitamos el gasto del Gobierno" (p. 63). Por tanto, se debe hacer lo siguiente.

3. Basta de austeridad. La hora de la austeridad se da en tiempos de auge, no de depresión, decía Keynes. "En una situación de profunda depresión económica y con las tasas de interés rondando el cero, los recortes de gastos no se pueden compensar y contribuyen a deprimir más la economía” (p. 207). Demasiadas personas de las que más pesan han elegido olvidar esta lección de la historia. ¿Interesadamente?

Aquí evoca el autor lo que él llama "la paradoja del ahorro" y que consiste en que conductas lógicas a niveles individuales pueden ser catastróficas a niveles colectivos $^{2}$. La austeridad y la abstención de consumo pueden (¡deben!) funcionar a niveles de una crisis individual, pero en el conjunto de una sociedad, "a medida que la economía ahonde en su estado de depresión, las empresas invertirán menos, no más". Y por eso, "en el intento de ahorrar más desde el punto de vista personal, los consumidores terminan ahorrando menos en conjunto" (p. 61). Por tanto, hay que activar la demanda y eso solo puede hacerlo el

2. Me permito poner un ejemplo personal: si está ardiendo tu casa, debes salir corriendo, pero si eso ocurre en un local donde hay miles de personas, pueden provocarse atropellos y muertes superfluas. 
Gobierno creando obra pública (y, si hace falta, imprimiendo dinero, que será una forma de devaluación).

El autor comenta largamente que esta fue también la lección de la guerra, que funcionó durante medio siglo. Por eso le parece incomprensible que, más tarde, a partir de la subida de Reagan, se eliminaran las regulaciones introducidas en la década de los treinta, como la ley Glass-Steagal (de 1933) que limitaba los riesgos que puede asumir un banco, y acabó siendo abolida por Clinton (p. 60). Resulta también inaudito que, en 2011, el presidente del BCE (Trichet) declarara que "la idea de que las medidas de austeridad podrían causar un estancamiento es incorrecta" (p. 200). Los hechos lo dejaron en ridículo, pues la austeridad ostentosa no hizo más que aumentar la desconfianza de los mercados ${ }^{3}$.

Tampoco Europa tendría por qué estar tan mal, con una deuda privada y pública inferior a la de EE. UU., con una inflación parecida y un balance más o menos equilibrado por cuenta corriente. El problema ha sido que Europa es solo una colección de países, pero no una unidad (p. 192). En esta situación de poca cohesión, "la creencia de que la crisis europea se debe ante todo a déficits presupuestarios excesivos por los que los países se endeudaron en exceso y por lo que ahora lo importante es establecer unas normas que impidan que la historia se vuela a repetir" (p. 190) ha sido lo que el autor califica como "el gran engaño europeo". En este contexto, Alemania ha adoptado un tono moralista con el que fustiga a los otros en interés propio (p. 33). Europa tenía que haber actuado como Islandia, cuyo desastre fue tan grande que no cabría esperar que estuviera hoy como está. Pero Islandia no se hizo responsable de las deudas de sus banqueros y dejó caer su moneda. El problema ha sido que muchos países europeos no tenían moneda propia (p. 194).

Aquí añade el autor una reflexión sobre el euro: "Una moneda común, sin haber creado antes la clase de unión política y económica que esa moneda común exige, se ha convertido en una fuente gigantesca de debilidad y crisis renovada" (p. 28). De hecho, los países del sur de Europa están menos endeudados de lo que está Japón o de lo que estuvo Inglaterra en gran parte del s. XX; su único problema es que, en tal situación, no tienen moneda propia como los otros países (pp. 151-152). Por eso, "desde principios de 2011, el euro ha supuesto una clara penalización: los países que usan el euro tienen que afrontar costes de préstamos más elevados que otros países con un panorama económico y fiscal parecido"

3. Esa misma mentalidad se refleja en nuestra ley de reforma laboral. Y cuando resulta que esa ley ha creado ochocientos mil parados más que en el mismo período del año anterior, cuando no existía, se atreven a decirnos que la ley ha funcionado porque sin ella, aun se habría creado más desempleo... Si no hay ahí intereses creados, "que venga Dios y lo vea". 
(p. 196). El BCE debió actuar paliando estos inconvenientes, pero los países más ricos se lo impidieron.

4. No temer a la deuda. El problema no es la deuda sin más: lo decisivo es quién debe el dinero (p. 157). Por eso, no supondrá ninguna tragedia que la deuda siga aumentando, a condición de que lo haga más lentamente que la inflación y el crecimiento económico (p. 152).

5. No temer a la inflación, que es otra "amenaza fantasma": "La realidad es que la inflación, de hecho, es demasiado baja y en Europa esto forma parte de una situación extremadamente dificultosa" (p. 178).

6. En conclusión, "los cambios en el gasto gubernamental mueven la producción y el empleo en la misma dirección: si se gasta más, crecerán tanto el PIB como el empleo, si se gasta menos, menguarán ambos" (pp. 225-226). "Si se pone dinero en manos de quienes lo necesitan, es muy probable que lo gasten y eso es exactamente lo que necesitamos que pase" (p. 229). Tanto lo necesitamos que eso es hoy obligatorio, porque "decenas de millones de nuestros conciudadanos atraviesan grandes dificultades, y las perspectivas de futuro de los jóvenes se debilitan con cada mes que pasa. Son principios económicos consagrados por el tiempo, cuya validez han reforzado aún más los acontecimientos recientes" (p. 243). Y por tanto, deberíamos saber que "los riesgos de hacer demasiado poco son muy superiores a los de emprender de más” (p. 228).

\section{Economistas frente a la Crisis (EFC), No es economía, es ideología, Deusto, 2012}

Los autores son un grupo de economistas, agrupados en la sigla EFC, que se manifiestan totalmente contrarios a las políticas imperantes para salir de la crisis. Todos coinciden en lo que insinúa el título del libro: la crisis se ha convertido en una coartada para cambiar nuestro modo de convivencia social (p. 10). Se produjo por falta de regulación y se quiere resolverla desregulando más: a eso que llaman hipócritamente reformas pero que, en realidad, son "contrarreformas" (p. 11). Y su objetivo es "reducir drásticamente la labor del Estado como redistribuidor de rentas" y "modificar los equilibrios entre empresarios y trabajadores en el seno de la empresa” (p. 42), quebrando la capacidad de los sindicatos.

Sobre esto incide "la lucha entre los Estados de la UE para aumentar su cuota de poder"; y algunos de ellos, "liderados por Alemania, no han resistido a la tentación de aprovechar la oportunidad para alcanzar una posición dominante, reduciendo a otros países a la condición de dependientes" (p. 43) mediante el control del BCE, del euro, del Banco Europeo de Inversiones y de pactos de estabilidad que estaban pensados para una situación normal de crecimiento y empleo, pero no para una situación de crisis. La clase política europea hace oídos sordos al clamor popular y "sigue haciendo del ajuste y de la austeridad su modo de enfrentar la crisis". 
Esto se debe a que "la mayoría de los dirigentes políticos no son economistas" y solo han aprendido "en dos tardes" unas pocas ideas escolásticas (p. 253), como si la economía fuera simplemente mecánica. Pero esas ideas escolásticas no funcionan en situaciones como la nuestra. Valga como ejemplo la necesidad de controlar la inflación, cuando, según el premio Nobel J. Stiglitz, "la idea de que el control de inflación traerá consigo la estabilidad entre la producción real y la potencial es esencialmente un error" (p. 256). Su defensa entonces se reduce a la repetida ideología de que toda propuesta alternativa "es perversa" (solo servirá para empeorar), "es inútil" (porque la economía funciona por leyes inalterables) y además supone "un riesgo demasiado alto" (p. 261). Atrincherados en estas "retóricas de la intransigencia" (A. O. Hirschman), desautorizan cualquier propuesta alternativa ya antes de que empiece a hablar.

Hay que añadir que, como todos los libros de varios autores, es desigual, pretende hablar de todo (finanzas, mercado de trabajo, fiscalidad, bancos, energía, medioambiente...) y algunos capítulos son minuciosamente técnicos. Pero se muestra muy crítico con nuestra ley de reforma laboral y comulga con la sensación de la calle de que todo lo que se está buscando es cómo salir de la crisis "sin que se vean afectados los más poderosos y más favorecidos" (p. 15).

\section{Juan Torres López, Contra la crisis, otra economía y otro modo de vivir, HOAC, Madrid, 2011}

En España, el autor no necesita presentación y es una de las voces más autorizadas entre los economistas críticos. Había participado, junto con Vicenç Navarro y Alberto Garzón en un libro anterior, asequible además en la red: Hay alternativas $^{4}$. En línea con los antes reseñados, incide en que las políticas contra la crisis solo servirán para enriquecer más y aumentar el poder de los grupos oligárquicos y para empobrecer más a millones de personas. Pese a estar hecho recogiendo artículos anteriores, el libro no carece en absoluto de unidad. Una primera parte analiza la crisis en España, desde el marco de un sistema que es "una maquinaria de empobrecimiento" y que ha contado con la complicidad de los bancos centrales. Dedica tres capítulos muy importantes a la desigualdad, y concluye con la tesis de que "otra economía es posible". Pero... es "una economía con más ética, más política y más amor" (título del epílogo).

El libro es de lectura asequible incluso para el profano como yo. Está escrito con un pathos contagioso, pone de relieve los silencios interesados que acompañan a muchas declaraciones de nuestros Gobiernos y abunda en infinidad de datos comparativos que ayudan a abrir los ojos y saber dónde estamos. Pongo

4. Prologado por N. Chomski, libro que la Editorial Aguilar se negó a publicar tras haberse comprometido a ello, y pudo aparecer en la Editorial Sequitur, con la colaboración de ATTAC España. 
dos ejemplos a boleo: "Un estudio de Consultores de Gobierno Corporativo señalaba que, a finales de 2006, diez familias y una veintena de empresarios (la mayoría de los cuales se enriquecieron y consolidaron su riqueza durante el franquismo) tenían en esa fecha bajo su control a 19 de las 35 mayores empresas cotizadas en España y eran propietarios del 20\% de su capital" (p. 66). Y otro ejemplo más global: en 2009 hubiesen sido necesarios 2,400 millones de dólares ${ }^{5}$ para salvar "a tres millones de madres y siete millones de recién nacidos". Pues bien, "solo el Banco de Santander y solo durante el primer trimestre de 2009 obtuvo un beneficio de 2,100 millones de euros... Y los Gobiernos europeos han destinado 3.7 billones de euros para el rescate bancario" (p. 24).

No es de extrañar, pues, que el autor se sume a estas palabras de Federico Mayor Zaragoza: "Hay que enfrentarse a esos sinvergüenzas que nos decían que no había medios para reducir a la mitad el hambre en el mundo en 2015, esos mismos que luego hablaban de 700,000 millones de dólares para rescatar a las financieras y decirles que ahora toca rescatar a los desfavorecidos".

Para terminar este capítulo podríamos decir que los libros presentados confirman el porqué del título del siguiente.

\section{Varios autores, Manifiesto de economistas aterrados, Ediciones Barataria, Barcelona, 2011}

Apareció en Francia en 2010 con la firma de más de 600 economistas que, al año siguiente, habían llegado a 3,000. Un librito breve (64 páginas) y bastante asequible, cuya preocupación era ver que, en medio del escándalo de las "subprimes" y demás perlas, las voces con más audiencia de nuestra economía seguían confirmando sin parpadear todos los principios del neoliberalismo que habían llevado a la crisis. El Manifiesto aspiraba sobre todo (aunque proponía también 22 alternativas) a desmontar "diez mitos" que constituyen el punto de partida de cualquier economía teórica actual y que son todos falsos. Por ejemplo, que los mercados financieros son eficientes, que favorecen el crecimiento público y juzgan bien la solvencia de los Estados; que hay que reducir gastos para reducir la deuda pública; y que hay que tranquilizar a los mercados para poder financiarla; que el euro era un escudo contra la crisis y que la crisis griega nos permitía avanzar hacia un modelo de solidaridad europea...

Lo que sobre todo provocaba el terror de esos economistas es que, "al no poner impuestos a los ricos, estos adquieren títulos de deuda pública (a la que se ven abocados los Gobiernos por la falta de ingresos fruto de esa falta de impuestos); y que luego hay que pagarles a los ricos los intereses de esa deuda".

5. Es decir, unos 1,800 millones de euros. 
Defender esa forma de economía no está lejos de la ceguera interesada de que hablaban las reseñas anteriores.

\section{Lecciones de la crisis para el futuro}

\section{Reinhard Marx, El capital. Un alegato a favor de la humanidad, Barcelona, 2011}

Ironías de la vida: en Trier (ciudad natal de Karl Marx), hubo hace poco un obispo llamado también Marx (hoy arzobispo de Múnich) que es economista y, además de manifestarse públicamente contra la guerra de Irak, nos regala otro libro con igual título que el de su homónimo: El capital. Con cierto sentido del humor, el libro lleva como prólogo una carta de este Marx a ese tatarabuelo nominal donde, tras manifestarle pocas simpatías, el arzobispo se pregunta, no obstante, si su antepasado no tendría razón en una larga serie de cosas. Esas cosas confluyen en dos puntos: (a) que también en economía, mi libertad termina donde comienza la libertad del otro; y (b) que, junto al llamado imperativo tecnológico (aquello que se puede hacer, hay que hacerlo), nos domina otro "imperativo económico" (cuando algo produce beneficios, hay que hacerlo), sin consideraciones humanistas o morales en ninguno de los dos casos. Así, un buitre norteamericano compró por 3 millones de dólares una deuda que tenía Zambia con Rumanía para comprar material agrícola, por valor de 15 millones. Pronto, Zambia se demoró en el pago, y nuestro amigo acudió a un tribunal de Londres que condenó al país africano a pagar 17 millones. Cuando la BBC le preguntó si no sentía escrúpulos por ello, respondió: "No es culpa mía. Yo lo único que he hecho ha sido una inversión" (pp. 138-139). Una "inversión" de los más elementales valores humanos, cabría aclarar...

El libro de este Marx resulta una apología de Amartia Sen y de O. Nell-Breuning de la "economía social de mercado" y de la doctrina social de la Iglesia (DSI), que el autor viene a resumir en que "la solidaridad y la subsidiariedad son principios fundamentales de configuración de la sociedad" (p. 180). Con todo, no llega a decir que esa DSI es inaplicable en nuestro sistema y, por tanto, hay que cambiar el sistema o la DSI no vale para nada. Algo que el mismo autor reconoce cuando afirma que considerar al trabajo como una mercancía más, sometida "a las leyes supuestamente inquebrantables del mercado", es incompatible con la DSI (p. 123).

Tiene de positivo que estructura toda la lucha por la justicia en torno a la idea de libertad, mucho más audible en nuestro mundo, y central también en K. Marx. Pero leamos: "No conozco ningún ejemplo histórico en que una economía libre de mercado, sin una cierta intervención y regulación por parte del Estado, haya sido beneficiosa en algún lugar del mundo para los pobres" (p. 83). O "cuando el Estado interviene (...) para asistir a la parte más débil, lejos de menoscabar 
la libertad lo que hace es abrir más espacios a la libertad" (p. 82). Y esas intervenciones incluirían, como mínimo, "la redistribución de la renta, el crecimiento económico sostenido, la lucha contra el desempleo y la protección del medioambiente" (p. 95).

Aleccionador es el capítulo 6 donde narra la historia de toda la crisis del 29, y deja al lector boquiabierto al ver cómo se repite la historia y qué poco aprendemos los hombres. Aquella crisis comenzó con una burbuja (no de vivienda, sino de acciones), negada como tal por los grandes gurús de la época. Se comenzaron a aplicar las mismas políticas que hoy, con resultados calamitosos: tanto que, en el inglés estadounidense, apareció la palabra "hoovervilles" (aludiendo al expresidente Hoover - como si hoy dijéramos rajoyburbios-) para designar a todos los barrios creados por el rápido aluvión de miseria. Hasta que Roosevelt propuso el famoso "new deal" (ganó con él las elecciones de 1932), aun con errores, comenzaron a arreglarse las cosas...

Hoy necesitamos otro "new deal" a escala mundial, y los políticos que "optan por dar prioridad a los intereses nacionales por muy 'comprensibles' que sean, parten de una base artificial y falsa" (p. 264). Porque la crisis actual puede no ser tan grave como la del 29 , pero "la cuestión social" es hoy más grave que nunca, porque ya no se trata de los que están arriba y los que están abajo, sino de exclusión: los que están dentro y los que están fuera (p. 111). Por eso, el obispo fustiga al FMI por no conocer, ni antes ni ahora, más políticas que las que agravan los problemas sociales (p. 269). También denuncia a "muchas facultades de ciencias económicas donde los estudiantes solo aprenden a realizar complicados cálculos econométricos", sin aprender conocimientos fundamentales (p. 292).

La conclusión es que "el fantasma de Karl Marx saldrá de la tumba para perseguirnos" (p. 299), a menos que seamos capaces de responder al desafío del momento. Pero esa respuesta supondría - ¡como mínimo!- acabar tanto con el desempleo europeo como con el empleo indigno (working poor) norteamericano" (p. 193). Lo cual, en mi opinión, vuelve muy probable la reaparición de ese temido fantasma, porque se trata de algo casi imposible para nuestro sistema.

Personalmente, me siento un poquito más a la izquierda que este obispo porque mi visón del hombre no prima el aspecto individual sobre el social (como él parece decir), sino que equipara a ambos en la línea de E. Mounier. Y porque le faltó hacer una reflexión sobre el "derecho de propiedad" según la moral católica. También echo de menos referencias, por ejemplo, a D. Schweickahrt y su democracia económica. Pero si la Iglesia tuviera hoy una larga serie de prelados como este, en lugar de esa especie de "tea party" episcopal que parece buscar la curia romana, daría al mundo un rostro mucho más creíble del Evangelio.

En cualquier caso, ese "fantasma de Marx" parece salir de la tumba en el libro siguiente. 


\section{Terry Eagleton, Por qué Marx tenía razón, Barcelona, 2011}

Buen libro, de lectura además agradable por el desenfado y la ironía británica de su autor. Pretende exponer "no la perfección de las ideas de Marx, sino su plausibilidad" (p. 11) aunque, en mi opinión, sobrepasa esa pretensión.

Después de Jesús (y con las debidas distancias), quizá no ha habido persona que haya sido, a la vez, seguida con más pasión y denostada con mayor rabia. Por eso, el autor intenta hacer un recorrido sereno, reconociendo los innegables méritos de Marx, pero también sus errores, las cuestiones que dejó abiertas y las atrocidades hechas apelando a su enseñanza (y de las que es tan responsable como puede serlo Jesús de los crímenes del cristianismo).

Su afirmación central es que el marxismo constituye "la más perspicaz, rigurosa y exhaustiva" crítica del capitalismo (p. 15). Por ser eso, tanto el marxismo como los médicos y los feminismos, aspiran a acabarse. Pero mientras existan, será señal evidente de que continúa habiendo enfermos, opresiones de género e injusticias sociales. No obstante, el libro está dedicado más a la filosofía social que a los análisis económicos de Marx, supongo que porque muchos desacreditan estos a partir de aquella.

En opinión del autor, el marxismo no aparece hoy derrotado por un triunfo del capitalismo, sino por la desesperación de este tras el boom de la posguerra y la creación de un Estado social por miedo al comunismo ruso. Esa desesperación envalentonó al sistema y acabó haciendo creer a muchos marxistas que este era invencible, dado que "aunque no tuviera la razón, tenía los tanques". Ejecutores de esa desesperación fueron Reagan y Thatcher, "quienes ayudaron (...) a fortalecer el brazo represor del Estado y a capitanear una nueva filosofía social: la de la más descarada codicia" (pp. 18-19). Desde entonces, el sistema tiene más poder que nunca para "propagar el cretinismo cultural, impulsarnos a la guerra, conducirnos como ganado a campos de trabajos forzados (...) y erradicarnos del planeta" (p. 21).

Esto pone en primer plano a la filosofía social y lleva al autor a preguntarse "por qué continuamos consintiendo el mito que abona la vana esperanza de que la fabulosa riqueza generada por el modo de producción capitalista acabará llegándonos a todos tarde o temprano" (p. 23) cuando, por ejemplo, un solo ciudadano mexicano tiene más dinero que 17 millones de compatriotas suyos juntos. Por eso busca dar una respuesta a todas las acusaciones hechas al comunismo, tratando de mostrar cuál era el pensamiento de Marx en cada uno de esos puntos. Y resulta muy convincente, aunque alguien pueda preguntar si no será una lectura de un visionario alemán filtrada por el pragmatismo inglés. Voy a detenerme más exponiendo un poco las acusaciones y respuestas.

1. A las acusaciones clásicas contra los países comunistas, responde el autor reconociendo su verdad. Pero (a) las acompaña de otra serie de acusaciones a 
los males causados por el capitalismo (ayer y hoy, y no solo económicas, sino políticas y humanas), las cuales se mencionan menos porque hoy es el sistema triunfante. (b) Esas acusaciones desconocen también todo el bien que aportaron en sus principios la Revolución rusa y la china. A pesar de todo, no tiene inconveniente en reconocer que "las ganancias del comunismo difícilmente superan sus pérdidas" (p. 29), como ocurre también en el capitalismo. Pero añade (c) que "Marx jamás imaginó que el socialismo fuera realizable en condiciones de especial pobreza" (p. 28) ni creyó eso ningún marxista hasta que llegó Stalin: porque el resultado solo sería la reaparición "de la misma mierda de siempre" (p. 29: cita literal de La ideología alemana). Tampoco imaginaron los marxistas en ningún momento que fuera posible alcanzar el socialismo en un solo país (p. 29); ese fue otro invento de "la monstruosa caricatura del socialismo conocida como estalinismo" (p. 32). Juzgar, pues, el socialismo por los resultados alcanzados en un único país "sería como extraer conclusiones sobre la raza humana a partir de un estudio sobre los psicópatas de Kalamazoo en Michigan" (p. 29). Marxistas como Trotski "fueron muy críticos con la economía planificada" (p. 36); lanzaron desde el primer momento, a las sociedades llamadas comunistas, críticas mucho más profundas que las hechas en Occidente; y predijeron, además, que si aquel sistema caía, "era muy posible que lo hiciera en manos de un capitalismo predatorio" (p. 34), como de hecho ocurrió.

Pero para Marx, "los mercados no son ni mucho menos privativos del capitalismo", pese a que el cambio climático es "el mayor fallo de mercado de la historia" (p. 28). Un socialismo de mercado "imagina un futuro en el que los medios de producción serían de propiedad social, pero donde existirían cooperativas autogestionadas que competirían entre sí en el mercado" (p. 35). Hay aquí un amplio debate ulterior que el autor deja abierto, no sin dedicar unas páginas a esos medios de comunicación de propiedad privada que Marx no conoció ("no tuvo nunca que vérselas con Fox News ni con el Daily Mail, por ejemplo": p. 58), y en los cuales "un puñado de matones avariciosos y ávidos de poder dictan (...) aquello que consideran que el público debe creer y opinar, o (lo que es lo mismo) las propias opiniones interesadas de esos pocos y el sistema que apoyan" (p. 40).

2. Tampoco es cierta la acusación de que Marx era un determinista, aunque tenga bastantes expresiones que pueden sonar así y a pesar de su optimismo voluntarista. Pero Marx sabía bien que "el determinismo histórico invita al quietismo político" (p. 56) y que "la historia no se sirve de los hombres como un medio para sus propios fines" (p. 60). El mismo grito posterior "socialismo o barbarie" muestra que en la historia hay, sí, posibilidades abiertas, pero no necesariamente usos correctos de ellas. El capitalismo, por tanto, no es un paso previo necesario que conduce inevitablemente al socialismo; solo cabe decir que "genera una enorme riqueza, pero lo hace de tal modo que inevitablemente la coloca fuera del alcance de la mayoría de los ciudadanos" (pp. 67-68). 
Las respuestas a esta objeción entran en largas reflexiones filosóficas ajenas a la intención de estas páginas, hasta vislumbrar "una cierta analogía con la interrelación cristiana entre la providencia divina y el libre albedrío humano" (p. 55). Tampoco es Marx demasiado original en la mayoría de sus conceptos y afirmaciones (hechas ya antes de él), salvo quizá en la vinculación entre "fuerzas de producción" y "relaciones de producción". De hecho, Marx creía que "solo con el capitalismo puede crearse suficiente excedente como para que sea posible la abolición de la escasez (y con ella, de la lucha de clases). Pero únicamente el socialismo puede llevar a cabo eso en la práctica" (p. 54).

3. Marx tampoco era un utopista iluso: combatió con rudeza a los socialistas utópicos y sería más fácil acusarle de una vaguedad imperdonable. Tampoco los profetas bíblicos pretendían predecir el futuro, sino denunciar el presente, y "Marx era un profeta, no un vidente" (p. 74). Para Marx, el futuro no está en el presente, como el pollito en el huevo, sino como un marco de posibilidades diversas, abierto y limitado a la vez. Cosa distinta es afirmar que el socialismo representa "una ruptura con el presente" (p. 80), con este presente injusto y cruel; y eso sí que lo pensaba Marx. Pero, al igual que la naciente Ilustración, "es más bien el capitalismo, no el marxismo, el que comercia con futuros", mediante sus “expertos adivinos" que pronostican ganancias seguras (pp. 73-74).

En sustancia, "la idea que Marx tiene de la emancipación rechaza tanto las continuidades sin sobresaltos como las rupturas totales". En ese sentido, puede decirse de él que es una criatura de lo más raro: "Un visionario que es, además, un sobrio realista" (p. 83). De lo que se trata en definitiva es de que los individuos no sean "libres de echarse al cuello los unos de los otros, como en la sociedad liberal, sino capaces de realizarse en y a través de la realización de otros individuos" (p. 91), aun sabiendo que "jamás podrá haber una conciliación completa entre individuo y sociedad" (p. 92). A eso aspira, por ejemplo, "el concepto de cooperativa autogestionada, unidad productiva clave del futuro según Marx" (p. 93).

El socialismo pretende ser, como la democracia, una salvaguarda de muchos posibles abusos de la maldad humana, que puede funcionar mejor o peor. Si Marx es muy pesimista respecto al pasado, se debe a que "los pensadores pesimistas prestan un mayor servicio a la emancipación humana que los ingenuamente optimistas", dado que "atestiguan una injusticia que pide a gritos un remedio". Pero es más optimista respecto al futuro porque "la mayor parte de ese funesto historial acumulado no era culpa nuestra", sino, en parte al menos, de unas estructuras sociales imperfectas (pp. 102-103). En todo caso, el autor termina haciendo suya la afirmación de T. Adorno: "Marx fue un enemigo de la utopía por el bien de la realización de esta” (p. 109).

Fundamentales en este modo de argumentar son tres presupuestos: (a) Marx creía (contra nuestra posmodernidad líquida) que existe "una naturaleza humana", 
lo que quiere decir un campo de posibilidades que acaba siendo limitado. (b) Creía, así mismo, que la igualdad no es uniformidad, no es "tratar del mismo modo a todo el mundo, sino ocuparse por igual de las necesidades diferentes de todos" (p. 108), porque "una persona no tiene libertad para ser lo que quiera cuando, al mismo tiempo, se está muriendo de hambre o ve impedido su crecimiento moral por una vida entera de trabajo pesado y casi insoportable" (p. 97). Y (c) otro presupuesto importante es la noción de clase media tan elogiada por Marx porque no es ni opresora ni oprimida; un detalle que sus enemigos prefieren ignorar (p. 107). Esa fue toda su utopía ${ }^{6}$.

4. Marx tampoco era un reduccionista económico. Que "sin producción material no puede haber civilización", lo acepta todo el mundo. Pero Marx pretende decir algo más: "Dicha producción es la que determina en última instancia la naturaleza de cualquier civilización" (p. 110). Sin embargo, como Engels se cansó de repetir, esto no significa ni "que las fuerzas económicas sean el único determinante" (p. 111), ni que esa determinación sea una causa mecánica: determinar significa "fijar unos límites al tipo de instituciones culturales, legales, políticas y sociales que se construyen" (p. 116).

En este sentido, hay una doble dirección entre la "base económica" y la "superestructura"; pero sigue siendo verdad que, grosso modo, las ideas dominantes provienen de la clase que constituye la fuerza dominante en la sociedad (p. 117). Esto lo va haciendo más evidente el paso del tiempo y pone de relieve que el verdadero reduccionista económico es el capitalismo ${ }^{7}$. Infinidad de testimonios, desde Rousseau hasta algunos "antisocialistas furibundos" (p. 119) coinciden en esto.

En cambio, lo que buscaba Marx era precisamente acabar con una producción hecha solo por raíces económicas para pasar a una producción "por sí misma": por el placer creador o la realización personal ${ }^{8}$. Pues el trabajo no puede ser

6. Permítase esta cita como ejemplo del estilo desenfadado del autor: "Es razonable creer que, en la sociedad comunista, abundarían los problemas, los conflictos y hasta las tragedias irreparables. Habría asesinatos de niños, accidentes de tráfico, novelas rematadamente malas, celos mortíferos, ambiciones desmesuradas, pantalones de mal gusto y penas inconsolables. Seguramente habría incluso que limpiar las letrinas" (p. 105).

7. Otra cita larga: "Pensemos por ejemplo en cómo la forma de la mercancía, propia del capitalismo contemporáneo, ha marcado con sus mugrientos dedos desde el deporte hasta la sexualidad, desde cómo ganarse un asiento en primera fila en el paraíso celestial hasta los tonos estridentes que utilizan los reporteros de la televisión estadounidense para captar la atención del espectador a fin de asegurarse ingresos publicitarios" (p. 117).

8. El mismo Marx, según nuestro autor, trabajó en este sentido: "Llegó a escribir poesía lírica, una novela cómica inacabada, un fragmento de una obra teatral en verso y un 
"una pura cuestión técnica o material", dado que "los seres humanos somos unos animales "significantes" (p. 122). A eso es a lo que en Grecia se llamaba "praxis" y de ahí tomó Marx la palabra.

En resumen, lo que Marx cree es que "solo lo económico, entendido en su sentido restringido, nos permitirá trascender lo económico" (p. 126). Y esa trascendencia es precisamente lo que el capitalismo impide.

5. Marx tampoco era un materialista: las cuestiones puramente especulativas le interesaban poco. Lo que hizo fue (en línea aristotélica) apartarse tanto de una filosofía meramente contemplativa como de un materialismo dominante que reduce a los humanos a pura materia manejable, para pasar a un materialismo superior que reconoce que los seres humanos "somos antes que nada materiales y corporales, pero no solo eso": somos sobre todo agentes 9 . Por tanto, que la conciencia humana sea corpórea "no quiere decir que no sea otra cosa más que cuerpo físico" (p. 130). Este modo de ver (y no los dos anteriores) toma en cuenta la existencia de los demás seres humanos, tan vinculada a cuestiones centrales como las de la necesidad o el deseo: pues "a través de los otros nos convertimos en lo que somos" (p. 134).

Pero Marx no podría haber sido un pensador de la historia si no diera una importancia decisiva al espíritu. Lo que quiere decir que las necesidades físicas no solo nos hacen pensar ${ }^{10}$, sino que además "moldean nuestra forma de pensar" (p. 143). Y que moldean no quiere decir que producen, sino que "si examinamos el derecho, la política, la religión, la educación y la cultura de las sociedades de clases, descubriremos que la mayor parte de lo que hacen sirve de apoyo al orden social imperante" (p. 150). Pero "el marxismo no es una teoría de todo" (p. 148)"

En conclusión: al igual que en la tradición bíblica (o en Aristóteles), lo espiritual, para Marx, "tiene que ver con dar de comer al hambriento, acoger a los inmigrantes y proteger a los pobres de la violencia de los ricos" (p. 139). Ese es su "materialismo".

6. Tampoco tiene una teoría ya obsoleta de la lucha de clases, que ya no valdría hoy porque se ha producido una difuminación entre la clase obrera y las clases

voluminoso tratado manuscrito no publicado sobre arte y religión. También tenía pensado poner en marcha una revista de crítica teatral y un tratado de estética. Sus conocimientos de la literatura mundial eran de una amplitud sorprendente" (p. 124). Detalles que yo desconocía.

9. Destacado en el original.

10. Como proclama el refrán castellano: "El hambre azuza el ingenio".

11. Según dice otra cita larga con el desenfado típico del autor: "Hay innumerables elementos que no pertenecen a la producción material ni a la llamada superestructura. El lenguaje, el amor sexual, la tibia, el planeta Venus, el amargo remordimiento, bailar el tango y los brezales de North Yorkshire son solo unos pocos de ellos" (p. 148). 
medias (p. 168). Pero las clases no se acaban porque los explotadores dejen de llevar corbata o vistan con vaqueros y zapatillas de tenis. Por eso es ridículo (por no decir algo más fuerte) que "haya en Occidente quienes buscan con evangélico fervor difundir la democracia liberal por el resto del planeta, en el preciso momento en que el destino del mundo está siendo determinado por un puñado de grandes empresas, con sede en Occidente, que no rinden cuentas ante nadie más que sus accionistas" (p. 159). En realidad, quien es enormemente "igualitarista" es el capitalismo, al reducirlo todo a mercancía.

Marx tampoco era sin más enemigo de la burguesía, a la que dedica grandes elogios en el Manifiesto: lo que quería es aprovechar sus logros y evitar que el capitalismo sea "una fuerza tan emancipadora como catastrófica" (p. 159), sin limitarse a bendecirlo por lo primero o satanizarlo por lo segundo. Tampoco pretendía mitificar ontológicamente a la clase obrera, sino aprovecharla funcionalmente: porque al ser, a la vez, "necesaria para el sistema capitalista y excluida por este" (p. 161), pone de relieve las contradicciones del sistema. Pero sabía bien que la clase obrera no podría hacer la revolución sin aliarse con otros grupos (campesinos, clases medias, administrativos o de servicios) $)^{12}$.

En conclusión, "solo aquellos para quienes la clase obrera se reduce a una cuestión de propietarios de fábricas ataviados con levitas y de obreros enfundados en sus monos de trabajo, podrían adherirse a una idea tan simplista" (p. 172).

7. Tampoco era Marx un promotor de una revolución violenta. Para empezar, en la historia se han dado tanto reformas violentas como revoluciones pacíficas ${ }^{13}$. Y quienes hoy se declaran contrarios a toda revolución violenta quieren decir casi siempre "que están en contra de algunas revoluciones, pero a favor de otras" (p. 176). Sin duda, tanto Stalin como Mao fueron asesinos de masas en proporciones increíbles, pero "muy pocos marxistas defienden hoy esos crímenes, a diferencia de muchos no marxistas que sí son capaces de defender la destrucción de Dresde o de Hiroshima" (p. 178), o las guerras hechas para controlar recursos energéticos o esferas de influencia imperial. Tampoco son los marxistas enemigos de la democracia, sino que consideran que la democracia parlamentaria es insuficiente (como han clamado y puesto de relieve los muchachos del 15-M). $\mathrm{Y}$ en cuanto a la violencia, "uno de los primeros decretos de los bolcheviques nada más llegar al poder fue la abolición de la pena de muerte” (p. 183). Lo que

12. Incluso, el término "proletariado" designa primariamente a mujeres, las que no pueden aportar a la sociedad más que la "prole": fuerza de trabajo en forma de hijos (p. 164).

13. Quizá valga la pena otra cita larga: "Las revoluciones se traman normalmente durante mucho tiempo y pueden tardar siglos en alcanzar sus objetivos. La clase media europea no abolió el feudalismo de la noche a la mañana. Tomar el poder político es una meta a corto plazo, transformar las costumbres, las instituciones y los hábitos de sentimiento de una sociedad lleva mucho más" (p. 174). 
no se puede es pretender llevar la revolución al extranjero e imponerla a punta de bayoneta, como hizo Stalin (p. 181).

En conclusión (y citando a W. Benjamin), "la revolución no es el tren que está fuera de control, sino el freno de emergencia con el que se intenta pararlo. Es el capitalismo el que está descontrolado" (p. 180). Pero el autor no comenta la frase de Marx sobre la violencia como "comadrona de la revolución".

8. Tampoco cree el marxismo en un Estado todopoderoso y despótico. "Marx se opuso implacablemente al Estado", aunque no a una administración central, indispensable en nuestra sociedad compleja (p. 188). El Estado existe en buena parte para defender el orden actual que es injusto, tanto que Marx anticipó ya la actual situación de dominio de los poderes económicos ("los amos del universo") sobre los políticos. Y esto vale también hoy, aunque haya un progreso sobre el feudalismo, en el que los poderes políticos eran los mismos económicos. Difícilmente pudo ser un apologista del Estado quien aplaudió la comuna de París, que era para él expresión de la "dictadura del proletariado" (fórmula muy desdichada que, según nuestro autor, no es de Marx, sino que la tomó de Auguste Blanqui).

En resumen, "el Estado que Marx aprobaba era el del dominio de los ciudadanos sobre sí mismos y no el de una minoría sobre una mayoría. Mientras que, según él, el Estado se ha apartado de la sociedad civil hasta el punto de que, entre ambos, existe una contradicción manifiesta" (p. 193). De todos modos, el autor reconoce que Marx fue ingenuo al ver en el poder solo una realidad instrumental, desconociendo lo que Freud y Nietzsche supieron ver: el atractivo que la voluntad de poder ejerce sobre el ser humano.

9. Se arguye finalmente que la verdadera izquierda está hoy en otros movimientos (feminismo, anticolonialismo, ecologismo). Es innegable, según el autor, que hubo marxistas que no distinguían el marx-ismo del mach-ismo, así como otros "que han realizado una gran contribución al pensamiento y a práctica feministas", y también que "buena parte de la obra de Marx ignora el factor género" (pp. 202-203), pese a que, para él, "la producción sexual y material son dos narraciones estrechamente ligadas entre sí”. En La sagrada familia llegó a afirmar que, "de entrada, la familia es la única relación social". Pero el hecho es que, hasta la aparición de los movimientos feministas, solo los comunistas se habían ocupado del tema: en la Rusia del 17, se creó un Secretariado Internacional de la Mujer y se convocó al primer congreso internacional de mujeres trabajadoras.

Algo parecido cabe decir respecto de la opresión colonial, pero aquí, pese a la abundancia de ejemplos posteriores, el mismo Marx fue muy ambiguo por su idea de que "algunas naciones solo son nacionalidades sin historia". En realidad, 
es otra vez el capitalismo (más que la clase obrera), el que no reconoce patria alguna (p. 211) $)^{14}$.

Y por lo que hace a la ecología, el autor cita dos frases: una de Engels ("la tierra es todo lo que tenemos y, por tanto, la condición primera de nuestra existencia") y otra de W. Lewis, para quien Marx representa "la más profunda intuición de la complejidad que rodea la cuestión del dominio sobre la naturaleza que haya tenido el pensamiento del s. XIX" (p. 216). De hecho, en El capital, se refiere Marx a la naturaleza como "el cuerpo de la humanidad con el que esta debe mantener un intercambio constante". Y añade que "el tratamiento consciente y racional del suelo en cuanto propiedad colectiva eterna es condición inalienable de existencia y reproducción de la serie de generaciones humanas" (pp. 217-218). En realidad es, otra vez, el capitalismo quien es incapaz de evitar la devastación ecológica por su impulso acumulador (p. 223).

10. Final. El autor cierra el libro con una conclusión-resumen que merecería ser citada íntegra si no resultase demasiado larga, y que termina con esta pregunta: “Ha habido alguna vez un pensador más caricaturizado?” (p. 226).

Podemos concluir la presentación destacando que la pretensión del autor ha sido mostrar que Marx sigue vigente no por ofrecer soluciones, sino por su diagnóstico del sistema capitalista ${ }^{15}$, el cual ayuda a comprender los dos grandes síntomas alarmantes detectados por Keynes: su incapacidad para crear trabajo digno y para reducir las diferencias abismales entre los seres humanos. Quizás falte más atención a la distinción de épocas en Marx: el joven filósofo y el maduro economista (que solo aparece al hablar del Estado). Pero, en cualquier caso, el autor aspira a poner de relieve la necesidad de cambiar el sistema, sin que tenga sentido discutir ahora sobre si ha de ser mediante reformas profundas o sustituyéndolo de golpe por un modelo alternativo. Esto último no es posible; pero lo primero exige que esas reformas sean verdaderamente profundas y no meros retoques de adorno, de modo que vayan llevando a un cambio del sistema.

\section{Conclusión "en cristiano"}

Lo menos que cabría pedir tras las presentaciones hechas es que el Presidente y su Gobierno dejen de repetir sonoramente (como El americano impasible, de Graham Greene) que están haciendo exactamente lo que tienen que hacer, que no hay otra política económica posible y que sus medidas nos llevarán pronto a un mañana mejor (parecido al de aquel verso sublime de Lope de Vega: "Siempre mañana y nunca mañanamos"). Cuando son tan claras las diferencias,

14. Aunque no pueda citarlo, en los momentos en que escribo es inevitable evocar las "transmigraciones" nacionales de Gérard Depardieu y otros de su misma calaña.

15. Diagnóstico muy bien hecho en la obra de E. Menéndez Ureña, Marx economista, Madrid, 1976. 
la más elemental sensatez y honradez política habrían pedido dialogar con todos y buscar entre todos la solución tratando de aportar todos, de ceder todos y, principalmente, de repartir equitativamente las cargas entre todos, en lugar de presentarse como "la única verdadera iglesia".

Es decir, si vimos decir a Krugman que lo que hay que hacer, a nivel económico, es lo contrario de lo que se ha hecho, cabe añadir que (aunque eso no fuese cierto a nivel económico) es muy cierto en el plano político.

Lo anterior queda dicho en un plan de sensatez política laica. Pero, además, quiero terminar con una reflexión creyente. Y esta podría arrancar de esta larga cita de Krugman:

El moderno conservadurismo se entrega a la idea de que las claves de la prosperidad son los mercados sin restricciones y la búsqueda sin trabas del beneficio económico y personal. También defiende que la expansión de las funciones gubernamentales, posterior a la Gran Depresión, solo nos ha supuesto perjuicios.

Sin embargo, lo que en verdad vemos es una historia en la que los conservadores se hicieron con el poder, se pusieron a desmantelar muchas de aquellas protecciones de los tiempos de la Depresión (...) y la economía se hundió en una segunda depresión notablemente negativa.

Esto que es muy evidente no será aceptado por todos aquellos cuyo sueldo depende de la no aceptación de estas ideas. Se buscarán paños calientes, remiendos insuficientes, y se intentará meter este vino nuevo en los viejos odres de siempre, para tranquilizar la propia conciencia. Pero las diferencias seguirán en pie porque, en realidad, el debate no es una cuestión de ideas ni de ciencia económica. Reclama una previa opción radical por los pobres y contra su pobreza. Sin creer que ellos ya pueden arreglarse con 400 euros, mientras que a Esperanza Aguirre un sueldo casi diez veces mayor "apenas le alcanzaba para llegar a fin de mes". Y sin argüir, tras una hecatombe de desempleo, que sin "la ley de reforma laboral (tan profundamente injusta), el paro habría subido todavía más", aunque los datos digan que en los 9 meses de vigencia de esa ley, ha habido 122 mil parados más que en esos mismos meses del año anterior. Y que los presupuestos calculaban unos 5 millones 600 mil parados y que hemos acabado el año con trescientos mil parados más...

Pero todo eso es normal dado que la mentira, o el eufemismo, son los dos ejes de nuestro sistema.

Porque de la crisis se saldrá, naturalmente, por la dinámica misma de las cosas. Y los economistas, según su militancia política o ideológica, atribuirán o no esa salida a las medidas de los Gobiernos. Pero, si para salir de la crisis ha sido necesario pisotear tiránicamente derechos primarios de los más débiles, y 
si tras la salida de la crisis esos derechos quedan mermados, se habrá puesto en evidencia la inmoralidad de un sistema cuyo fin justifica toda una serie de medios inmorales. Habremos salido de la crisis económica, pero no de nuestra crisis de humanidad. Y, probablemente, al cabo de un tiempo se cumplirá aquel refrán que cabe parafrasear así: "El hombre es el único animal que tropieza mil veces en la misma crisis".

Porque solo con un contacto personal y frecuente con los rostros de las víctimas, solo con una caída del caballo como la de san Pablo, podrá tener alguna solución nuestra crisis de humanidad, encaminándonos hacia una "civilización de la sobriedad compartida".

Pero quienes hagan una opción así se verán tratados de embusteros, agitadores, soflamáticos, revolucionarios o, en el mejor de los casos, de ingenuos. La tradición cristiana ha dicho infinidad de veces que los pobres serán nuestros jueces: nosotros preferimos olvidar ese juicio y presentarnos ante el tribunal de una supuesta "ciencia" económica y de la gran prosperidad de unos pocos. Y así solo conseguimos seguir prisioneros de aquel homicida radical a quien Jesús calificaba significativamente como "el padre de la mentira". 